\title{
A COMPACT VERY-HIGH-PERMITTIVITY DIELECTRIC-EYE RESONATOR ANTENNA FOR MULTIBAND WIRELESS
}

APPLICATIONS

Elinu Paul, ${ }^{1}$ S. Mridula, ${ }^{1}$ P. Mohanan, ${ }^{1}$ P. V. Bijumon, ${ }^{2}$ and M. T. Sebastian ${ }^{2}$

${ }^{1}$ Centre for Research in Electromagnetics and Antennas (CREMA) Department of Electronics

Cochin University of Science and Technology Kochi 682 022, Kerala, India

${ }^{2}$ Ceramics Technology Division

Regional Research Laboratory

Thiruvananthapuram 695 019, Kerala, India

Received 31 March 2004

ABSTRACT: A very-high-permittivity $\left(\varepsilon_{\mathrm{r}}=100\right)$ multiband dielectriceye resonator antenna is presented. The compact antenna, excited by a microstrip line, resonates at two frequencies centered around the 1.9$\mathrm{GHz}$ and 2.4-GHz bands with identical polarization. The behavior of the antenna at different positions along the feed line is studied and optimized. Multiple resonances with the same polarization and broad radiaticn patterns suggest the suitability of the antenna for multiband wireless applications. (1) 2004 Wiley Periodicals, Inc. Microwave Opt Technol Lett 43: 118-121, 2004; Published online in Wiley InterScience (www.interscience.wiley.com). DOI 10.1002/mop.20394 
Key words: dielectric resonator antenna; multiband wireless applications

\section{INTRODUCTION}

The development of numerous mobile-communication systems has led to increased demand for compact, efficient antennas. Small integrated antennas play a significant role in the progress of the rapidly expanding military and commercial communications applications. Recently, with the booming wireless mobilecommunications market, the urgency to design compact multiband antennas is even more pronounced [1-3]. Dielectric resonator antennas (DRAs) are attractive to antenna designers due to their excellent radiation characteristics. In addition, this class of antennas exhibits all the desirable characteristics of a microstrip antenna. Since its inception in the early 1980s, there has been a steady progress of research in this area over the years [4-6]. S. Mridula et al. [7] studied the reflection and radiation characteristics of a microstrip-line-excited rectangular DRA. In this paper, we propose an eye-shaped DRA suitable for wireless applications.

\section{ANTENNA GEOMETRY}

The antenna is comprised of an eye-shaped dielectric resonator (DR), excited directly by a $50 \Omega$ microstrip line of width $3 \mathrm{~mm}$ and fabricated on a substrate of dielectric constant $\varepsilon_{r}=4.28$ and thickness $1.6 \mathrm{~mm}$. The DR is made of very high permittivity $\left(\varepsilon_{r}=100\right)$ ceramic material $\mathrm{TiO}_{2}$ doped with 1 mole $\% \mathrm{Fe}_{2} \mathrm{O}_{3}$ prepared using conventional solid-state ceramics. The eye shape is defined by the intersection of two identical circles of radius $31.5 \mathrm{~mm}$ with their centers displaced by $7.5 \mathrm{~mm}$, as shown in Figure 1. A broadband dual-frequency oval-shaped microstrip antenna was proposed by M. Deepukumar et al. [8]. This novel geometry provides two independent ports with or. thogonal polarization and excellent isolation between the two ports. However, in this paper dual-band operation is obtained by exciting the various resonant modes of the eye-shaped DRA by using a single feed. The DR can be placed in two orthogonal orientations upon the feed line. Figure 2 illustrates the two configurations of the antenna. To the best knowledge of the authors, a DRA with this novel geometry has not been reporter until now.

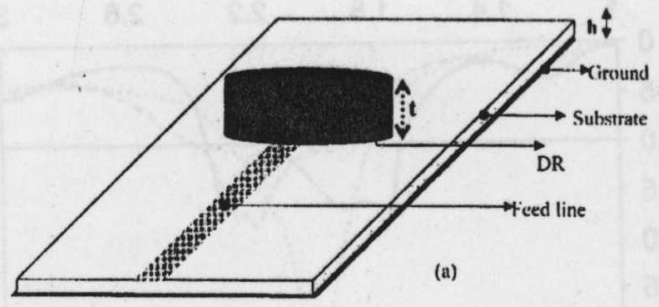

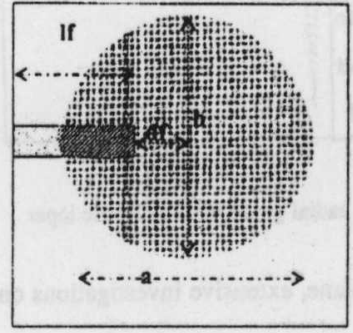

(b)

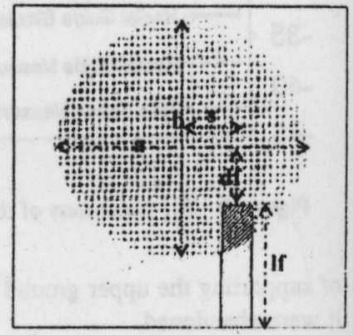

(c)
Figure 2 Geometry and configuration of the DRA: (a) geometry of the proposed eye DRA ( $h=1.6 \mathrm{~mm}, t=7.5 \mathrm{~mm}$ ); (b) top view of configuration $1(a=30.5 \mathrm{~mm}, b=23.5 \mathrm{~mm}$, lf $=35 \mathrm{~mm}, d f=12.5$ $\mathrm{mm})$; (c) top view of configuration $2(a=30.5 \mathrm{~mm}, b=23.5 \mathrm{~mm}$, lf $=$ $35 \mathrm{~mm}, d f=6 \mathrm{~mm}, s=7.5 \mathrm{~mm}$ )

\section{EXPERIMENTAL RESULTS}

The DR is excited directly by a microstrip line of length $35 \mathrm{~mm}$. It is moved symmetrically along the feed line and the variation in return loss as a function of frequency is studied for various positions. The measurements are repeated for the orthogonal orientation of the DR upon the feed line. Numerous resonant modes of the DRA are observed, with the most prominent being the bands centered around $\sim 1.9$ and $\sim 2.4 \mathrm{GHz}$. The position of the DR along the feed line is experimentally optimized for minimum return loss. The return loss at the optimum position of the DR is plotted in Figure 3 for configuration 1. The antenna exhibits $2.4 \%$ and $0.97 \% 2: 1$ VSWR bandwidth at these two frequencies, respectively.

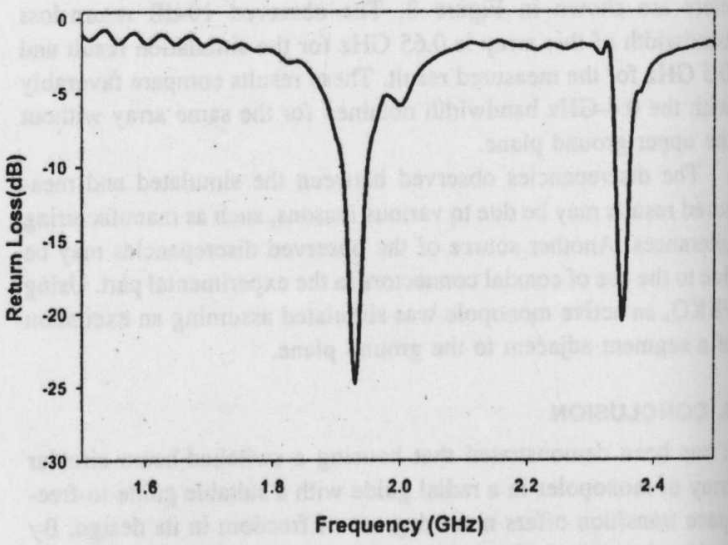

Figure 3 Return loss at the optimum symmetrical position of the DR placed in configuration 1: $F 1=1.93 \mathrm{GHz}(1.907-1.958 \mathrm{GHz})$ at $2.4 \%$ bandwidth; $F 2=2.353 \mathrm{GHz}(2.343-2.365 \mathrm{GHz})$ at $0.97 \%$ bandwidth
Figure 1 Two identical circles of radius $r$ and center-to-center spacing $d$, intersecting to form the eye geometry $(r=31.5 \mathrm{~mm}, d=7.5 \mathrm{~mm}, a=$ $30.5 \mathrm{~mm}, b=23.5 \mathrm{~mm}$ ) 


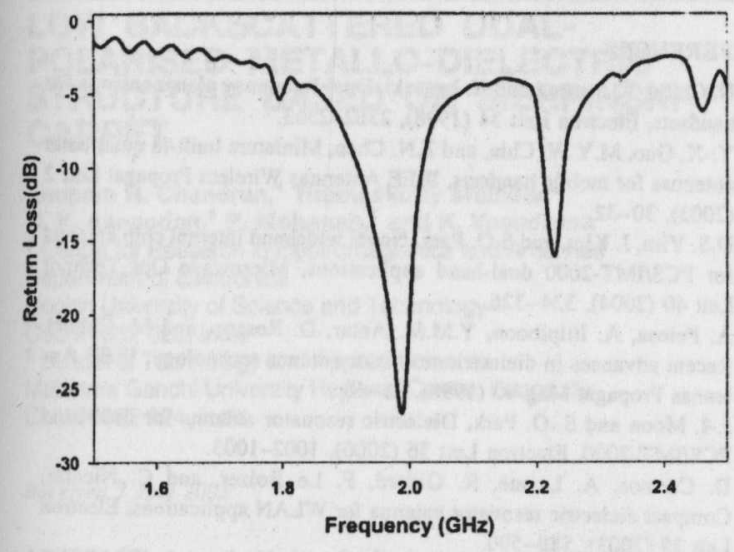

Figure 4 Return loss at the asymmetrical position of the DR placed in configuration $2: F 1=1.99 \mathrm{GHz}(1.917-2.02 \mathrm{GHz})$ at $5.17 \%$ bandwidth; $F 2=2.23 \mathrm{GHz}(2.215-2.245 \mathrm{GHz})$ at $1.1 \%$ bandwidth

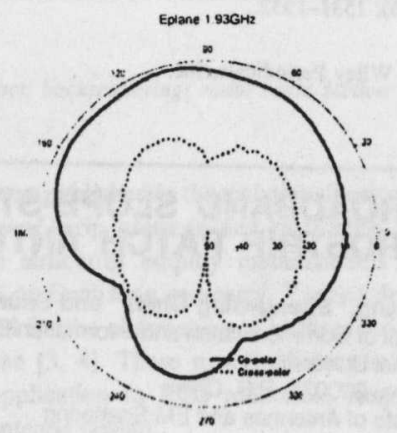

(a)

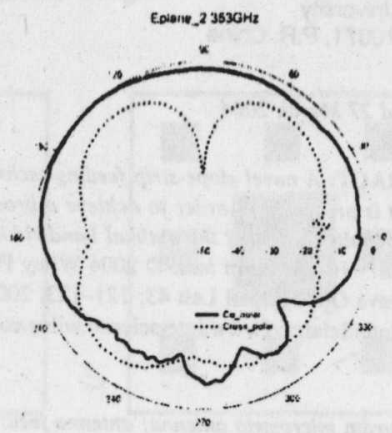

(b)

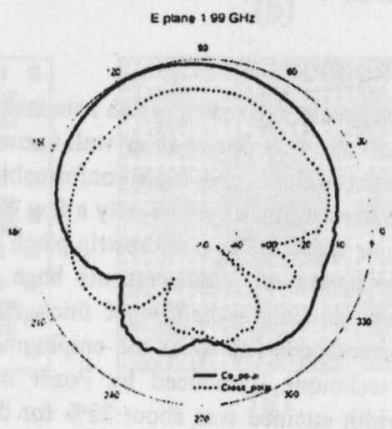

TABLE 1 3-dB Beamwidth of the Proposed Antenna in Different Configurations

\begin{tabular}{lccc}
\hline & \multicolumn{2}{c}{ Configuration 1 } & \\
\cline { 2 - 4 } & Band 1 & Band 2 & Configuration 2 \\
\hline E-plane & $98^{\circ}$ & $122^{\circ}$ & $84^{\circ}$ \\
H-plane & $94^{\circ}$ & $102^{\circ}$ & $86^{\circ}$ \\
\hline
\end{tabular}

The 2:1 VSWR bandwidth exhibits considerable increase for the asymmetrical positions of the DR upon the feed line. Figure 4 illustrates the reflection characteristics of the DR placed asymmetrically upon the feed line for configuration 2 . Here, the bandwidth of operation is $\sim 5 \%$ and $1 \%$ at 1.99 and $2.23 \mathrm{GHz}$, respectively.

The radiation pattern of the DRA is measured using an HP $8510 \mathrm{C}$ Network Analyser. Figure 5 shows the measured radiation patterns of the DRA. The patterns are reasonably broad in both $\mathrm{E}$ - and $\mathrm{H}$-planes, thus indicating the usefulness of the proposed antenna configuration for wireless applications. The
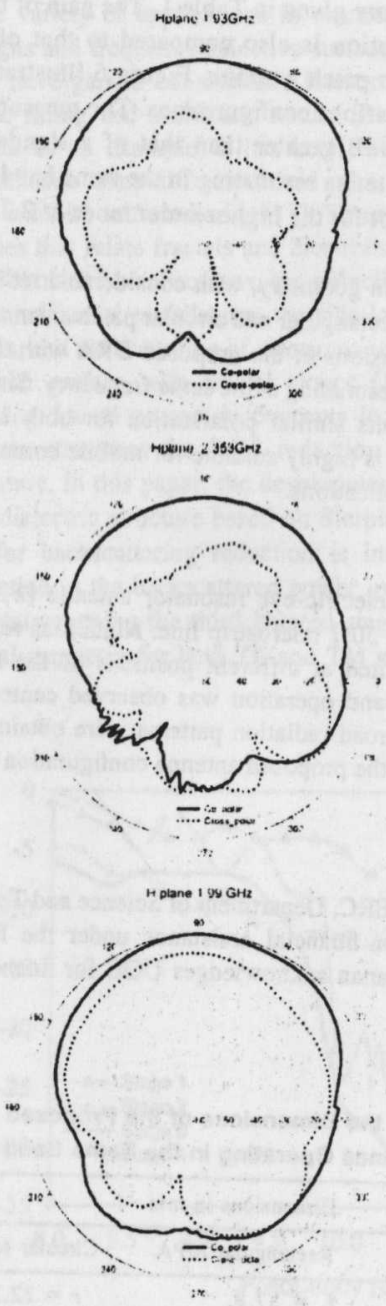

Figure 5 Radiation patterns of the DRA placed in different configurations: (a) configuration 1 in the first band centered at $f=1.93 \mathrm{GHz}$; (b) configuration 1 in the second band centered at $f=2.353 \mathrm{GHz}$; (c) configuration 2 in the band centered at $f=1.99 \mathrm{GHz}$ 


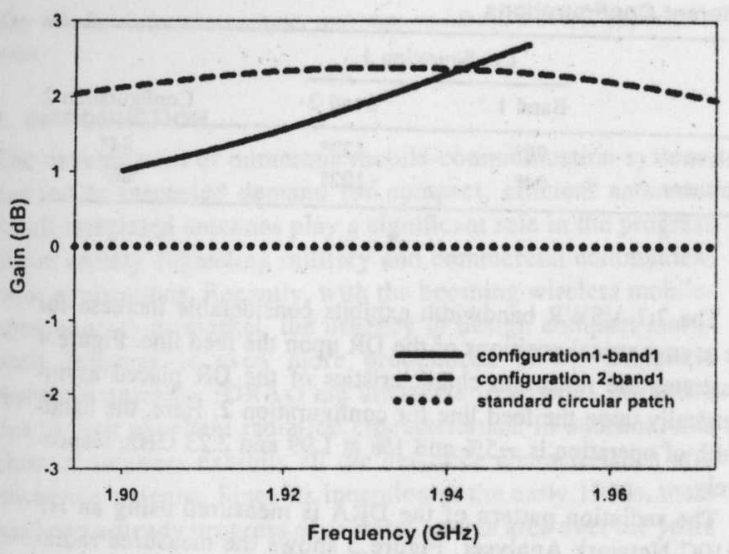

Figure 6 Gain of the proposed antenna placed in different configuration;

3- $\mathrm{dB}$ beamwidths obtained are given in Table 1 . The gain of the proposed antenna configuration is also compared to that of a standard circular microstrip patch antenna. Figure 6 illustrates the gain of the antenna in various configurations. The measured gain of the antenna is $\sim 2-\mathrm{dB}$ greater than that of a standard circular microstrip patch antenna resonating in the same band in all the configurations, except for the higher-order mode at 2.353 $\mathrm{GHz}$.

The antenna is compact in geometry, with considerable reduc. tion in area as compared to rectangular and circular patch antennas. Table 2 compares the dimensions of the proposed DRA with that of other microstrip patches resonating at the same frequency. Since the proposed antenna exhibits similar polarization for both 1.9. $\mathrm{GHz}$ and $2.4-\mathrm{GHz}$ bands, it is highly suitable for mobile communications and Bluetooth applications.

\section{CONCLUSION}

A very-high-permittivity dielectric-eye resonator antenna $\left(\varepsilon_{r}=\right.$ 100 ) has been excited by a $50 \Omega$ microstrip line. Numerous resonant modes have been excited at different positions of the DR along the feed line. Dual-band operation was observed centered around 1.9 and $2.4 \mathrm{GHz}$. Broad radiation patterns were obtained, suggesting the relevance of the proposed antenna configuration for wireless applications.

\section{ACKNOWLEDGMENTS}

S. Mridula acknowledges SERC, Department of Science and Technology, Govt. of India, for financial assistance under the Fast Track Scheme and P. Mohanan acknowledges UGC for financial support.

TABLE 2 Comparison of the Dimensions of the Proposed Antenna with Patch Antennas Operating in the Same Band

\begin{tabular}{lclc}
\hline \multirow{2}{*}{$\begin{array}{l}\text { Resonant } \\
\text { Frequency }\end{array}$} & \multicolumn{3}{c}{ Dimensions in mm } \\
\cline { 2 - 4 } & Eye DRA & Rectangular MPA & Circular MPA \\
\hline $1.9 \mathrm{GHz}$ & $a=30.5$, & $L=37.8$, & $r=22.35$ \\
& $b=23.5$, & $W=48.6$ & \\
& $t=7.5$ & $L=29.8$, & $r=17.7$ \\
$2.4 \mathrm{GHz}$ & & $W=38.5$ & \\
& & & \\
\hline
\end{tabular}




\section{REFERENCES}

1. N. Chiba, T. Amano, and H. Iwasaki, Dual-frequency planar antenna for handsets, Electron Lett 34 (1998), 2362-2363.

2. Y.-X. Guo, M.Y.W. Chia, and Z.N. Chen, Miniature built-in quad-band antennas for mobile handsets, IEEE Antennas Wireless Propagat Lett 2 (2003), 30-32.

3. D.S. Yim, J. Kim, and S.O. Park, Novel wideband internal chip antenna for PCS/IMT-2000 dual-band applications, Microwave Opt Technol Lett 40 (2004), 324-326.

4. A. Petosa, A. Ittipiboon, Y.M.M. Antar, D. Roscoe, and M. Cuhaci, Recent advances in dielectric resonator antenna technology, IEEE Antennas Propagat Mag 40 (1998), 35- 48.

5. J.-I. Moon and S.-O. Park, Dielectric resonator antenna for dual-band PCS/IMT-2000, Electron Lett 36 (2000), 1002-1003.

6. D. Cormos, A. Laisne, R. Gillard, F. Le Bolzer, and C. Nicolas, Compact dielectric resonator antenna for WLAN applications, Electron Lett 39 (2003), 588-590.

7. S. Mridula, S.K. Menon, P. Mohanan, P.V. Bijumon, and M.T. Sebastian, Characteristics of a microstrip-excited high-permittivity rectangular dielectric resonators antenna, Microwave Opt Technol Lett 40 (2004), 316-318.

8. M. Deepukumar, J. George, C.K. Aanandan, P. Mohanan, and K.G. Nair, Broadband dual-frequency microstrip antenna, Electron Lett 32 (1996), 1531-1532.

(1) 2004 Wiley Periodicals, Inc. 